\title{
Automated conveyor system for football quality checking
}

\author{
Muhammad Rusydi Muhammad Razif, S. A. H. J. Norazuan, Ili Najaa Aimi Mohd Nordin, \\ Hairulazwan Hashim \\ Faculty of Engineering Technology, Universiti Tun Hussein Onn Malaysia, Malaysia
}

\begin{tabular}{|c|c|}
\hline Article Info & ABSTRACT \\
\hline Article history: & Many incidents happen in football matches such as injury, fight between team \\
\hline Received Jan 2, 2019 & and ball out of game as whistle is blow. The worst case is where the ball \\
\hline Revised Apr 15, 2019 & reduce problem in football matches and ensure the quality of the football match \\
\hline Accepted May 3, 2019 & specification, this project is proposed a conveyor system for football quality \\
\hline Keywords: & $\begin{array}{l}\text { system, a conveyor belt is introduced as a medium for conveying the ball, } \\
\text { sensors to check the football specification and microcontroller to read the }\end{array}$ \\
\hline Automation & sensor input and produce output in term of motor control and measurement \\
\hline Conveyor system & $\begin{array}{l}\text { display. The conveyor system is made for checking the FIFA standard ball } \\
\text { specification and it was built portably for easily carry and used in sport shop. }\end{array}$ \\
\hline Football & The system could operate automatically, thus reducing to the need for worker. \\
\hline Quality checking & This project is expected to reduce injury in football match and also ensure the \\
\hline Size and weight & $\begin{array}{l}\text { quality of the ball is guaranteed. For a standard football size measurement, the } \\
\text { ball weight shows almost similar to the standard specification with } 20 \mathrm{~g} \\
\text { differences. }\end{array}$ \\
\hline
\end{tabular}

Copyright $@ 2019$ Institute of Advanced Engineering and Science. All rights reserved.

\section{Corresponding Author:}

Muhammad Rusydi Muhammad Razif,

Faculty of Engineering Technology,

Universiti Tun Hussein Onn Malaysia,

84600 Muar, Johor, Malaysia.

Email: rusydi@uthm.edu.my

\section{INTRODUCTION}

Football or soccer has become one of the biggest sport in the world. Every country produces a league and national team to become the best. The most popular cup in the world is Federacion Internationale de Football Association (FIFA) World Cup where national team do their best to win this cup in order to become the world champion. The quality of the football must be at the best where players could perform in any match at their best performance. For more than a decade, researcher has focusing the studies on various kind of sports ball such as tennis, golf, baseball, football, volleyball and many others [1-4]. Among those particular sport balls, the football has the largest dimension and weight [5].

The football need in best quality to avoid any delayed or influences in a match. The introduction of automated conveyor functioning to check the quality of the soccer ball is one of the solution to ensure the football specification meet their standard. There are three main standard requirements in football quality measurement [6]. The first one is the size of the football. The size of the football need to be in range as it can influence the performance of the player during the match. The second one is the air pressure for the football. We need to ensure that the air pressure for the soccer ball is good enough before being used. The last one is the weight of the football. The weight of the ball need to be in the condition where it is not too heavy nor too light. If the football is too heavy, the trajectory of the ball moving will be affected, whereas if it is too light, the ball will easily soar [7]. Many of these cases had happened during football match where the ball was burst. One of the examples of the case is a match between Bayern Munich FC and FC Koln for Bundesliga in 
Germany League. It was a free kick situation outside the FC Koln penalty area, taken by Daniel van Buyten. The ball blocked by the FC Koln's defender, Cologne, hits his boot stud and the ball was bursts [8].

In recent study, the number of panels on the ball, their orientation and shape of the panel play important part in fluid dynamic of the ball to produce stable trajectory. Previously, the study on aerodynamic has been conducted to the ball with 6,8 and 14 number of panels compared to the traditional 32 number [9-10]. In 2014, the researcher found that the official ball in the 2014 FIFA World Cup held in Brazil with 6 panels produce more stable trajectories [11-12]. Later in 2016 EURO Cup, the official ball panel shape has been totally different because the arrangement of panel has been set to be small uneven uniformly arranged square projection and the roughness of the ball surface has been changed. This led to a totally different aerodynamic characteristic or flight trajectory which has not been clearly understood [13]. In determination of aerodynamic characteristic, critical Reynolds number has often been studied. The Reynolds number could be defined as an indicator directly linked to the ball velocity and flight trajectory. The clarification of its value has been considered very important in sports science, sports engineering and competitive arena [14]. With the advanced in computer technology, the study of aerodynamic could be done in 3D analysis by using Computational Fluid Dynamic (CFD) technique [15]. By CFD analysis, the drag, lift, side force and pressure distribution could possibly be done by using surface wrapping meshing method and the Reynolds-Averaged Navier-Stokes approach [16].

The concern in quality checking is to ensure the materials are in a good quality. To achieve that, the conveyor systems for checking the materials need to be installed with many sensors and running in orders. Usually in every automated conveyor system, several stations were installed, and every material need to pass the checking station and the sensors embedded in each station will function as the quality checking to prevent any rejection material from being sold [17]. In recent years, some of the quality checking work has been conducted using Bayesian theorem [18-19]. For example, Panagiotidou et al. [20] in their report mentioned that the quality checking of the product occurs by updating the defect probability using Bayesian theorem. In some of advanced cases, the Bayesian theorem has been integrated with other method such as Poisson-Gamma for uncertainties in non-conformance rates [21] and Bayesian Belief Network for a risky production line [22].

Based on the previous study, the most common things to check in football is the size, pressure and the weight of the ball. The standard size of a football is roughly $22 \mathrm{~cm}$ ( 8.65 inches) in diameter for a regular size 5 ball. The dimension come from the rule that stated a size 5 ball must be 68 to $70 \mathrm{~cm}$ in circumference. The numbers are then dividing by $\pi$, giving the average reading about $22 \mathrm{~cm}$ in diameter.

For the weight, the ball must be in the range of 410 to 445 grams (14 to $16 \mathrm{oz}$ ) and inflated to a pressure of between 0.6 and 1.1 standard atmospheres ( 8.8 and $16.2 \mathrm{psi})$ at sea level [23]. In order to make sure the ball is in the perfect weight; we need to measure its mass by using sensitive digital scale that can measure the light material [24]. Standard ball weight is about $410 \mathrm{~g}$ to $445 \mathrm{~g}$, thus the digital scale with the range of 0 to $500 \mathrm{~g}$ and $0.1 \mathrm{~g}$ sensitivity is the most acceptable to be used in measuring the ball.

\section{RESEARCH METHOD}

The automated conveyor system for football quality checking build in this project, use motor, conveyor belt, several sensors and LCD display. A motor is used to control and move conveyor belt on one direction. Conveyor belt is used to move the football and passing through all the sensors in checking stations. There are three sensors use to check the quality of football. The first one is IR sensor that uses to check the size of the ball. Then, the other IR sensor is used to stop the motor for a few seconds in order the get the stable weight for the ball. Lastly, the load cell sensor uses to check the weight of the ball. All of this sensor will check the ball according to FIFA specification.

For the whole checking process, initially a ball is placed on the conveyor system. Then the ball will start moving to first station for size checking. The size of the ball then detected by the IR sensor and the LCD will display the size of football. Then the ball will move to the second station for weight checking. In this station, another IR sensor is used to detect the position of the football and it will stop the motor for a few seconds to measure the weight of the ball. For measuring the football weight, a load cell is used and it has been placed under the conveyor belt. Then the LCD will display the weight of the ball. After passing through the weight checking section, the ball will move out from the conveyor.

In controlling the automated conveyor system, Arduino is used as microcontroller to control the whole system. Arduino is known as an open source platform, and it contains both a physical programmable circuit board and a software called Integrated Development Environment (IDE) that runs on computer that used to write and upload computer code to the physical board [25].

Before executing the coding, the flow or algorithm of the project need to be set. The first process started with turning on the conveyor system and it end with the weight measurement. During the checking section the LCD will display the size of the ball at the whether it is 5 or not. After that, the ball moves to the 
weight checking and the LCD will display the weight of the ball in gram unit. Lastly, the ball will exit the conveyor. Figure 1 describe the whole process of ball quality checking.

Automated conveyor system for football quality checking can be illustrated as in Figure 2. The main part of this system is conveyor belt that controlled by a motor. Above the conveyor, this system contains of two count sensors and one LCD display to display and record the ball measurement before and after checking.

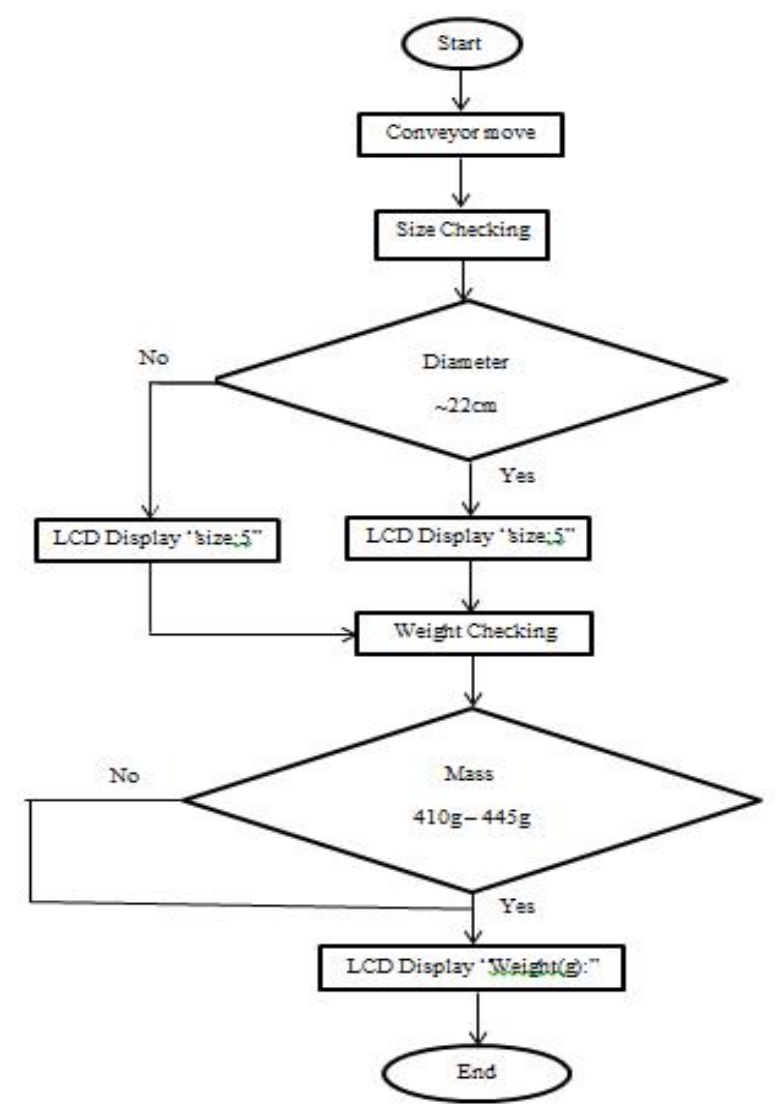

Figure 1 . The whole process of ball quality checking

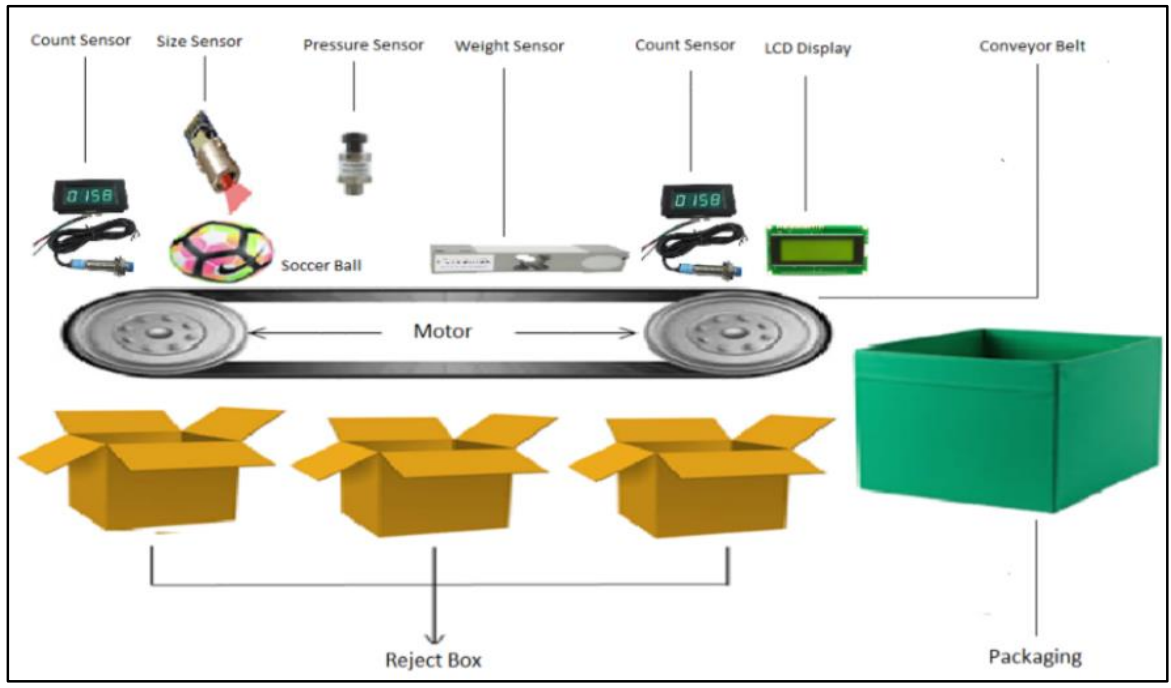

Figure 2. Experimental setup for automated conveyor system for football quality checking 


\section{RESULTS AND ANALYSIS}

After all the components and parts was successfully built and assembled, the testing and analysis was conducted in order to determine whether all of the system components are functioning well and does not have any problems. The analysis that is done involve the electrical components, the mechanical parts and also the related problems and issues that have been faced during the development process.

For every analysis, the results were compared to the theoretical values that were gotten from the simulation or calculation. The conveyor system has $0.9 \mathrm{~m}$ length and it operated by a servo motor. From the observation, the conveyor system will move at average of 1 minute to complete one cycle rotation system. The speed is getting lower as the load on the top of the conveyor system increase. From the investigation, the speed of the conveyor is slow due to the lower torque produced by the motor (50rev/min). This could be improved by replacing the motor with higher torque performance. Figure 3 shows the configuration of the conveyor system.

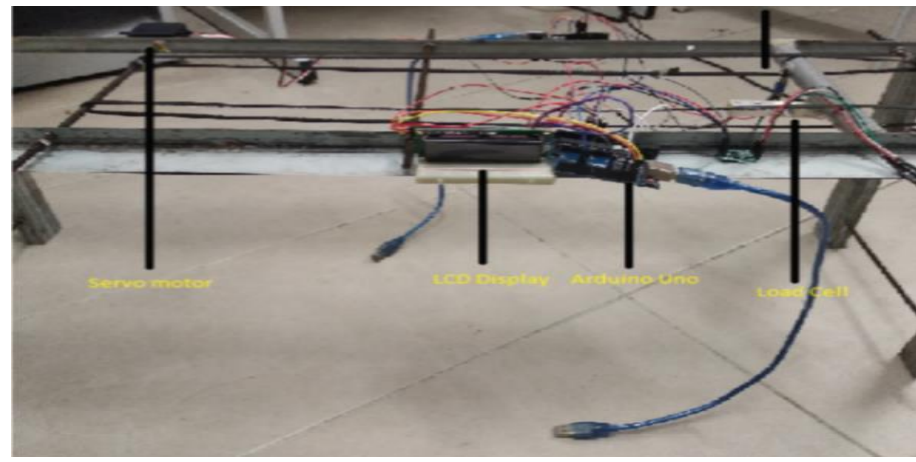

Figure 3. Configuration of the conveyor system

In driven the conveyor system smoothly, servo motor is used to drive the rotation of the conveyor system. It must attach firmly in order to avoid the roller from uprooted while rotating. However, it is a challenge to attach the servo motor to the conveyor due to the material differences where the roller of the conveyor is iron while the servo motor gear is plastic and the sizes of both are not matching.

In weight measurement, load cell has been attached at the center of the conveyor so that the bottom part of the ball could touch the sensor. It also has to attach firmly to ensure the load cell unmovable. The load cell used the HX711 module to convert from the analog signal to digital signal. It also need to initially be calibrated in order to make the result display on the LCD. Based on the graph in Figure 4, it shows that the amplitude of football of the load cell amplifier $(\mathrm{mV})$ is increasing with the increment of the weight. For the standard football size, the weight should be in the range of $410 \mathrm{~g}$ to $445 \mathrm{~g}$, or $118 \mathrm{mV}$ to $125 \mathrm{mV}$ in weight sensor. Our measurement within real football testing shows almost similar to real football specification with the difference of $20 \mathrm{~g}$. This is due to the originality of the ball's material used in our testing and world specification might be different.

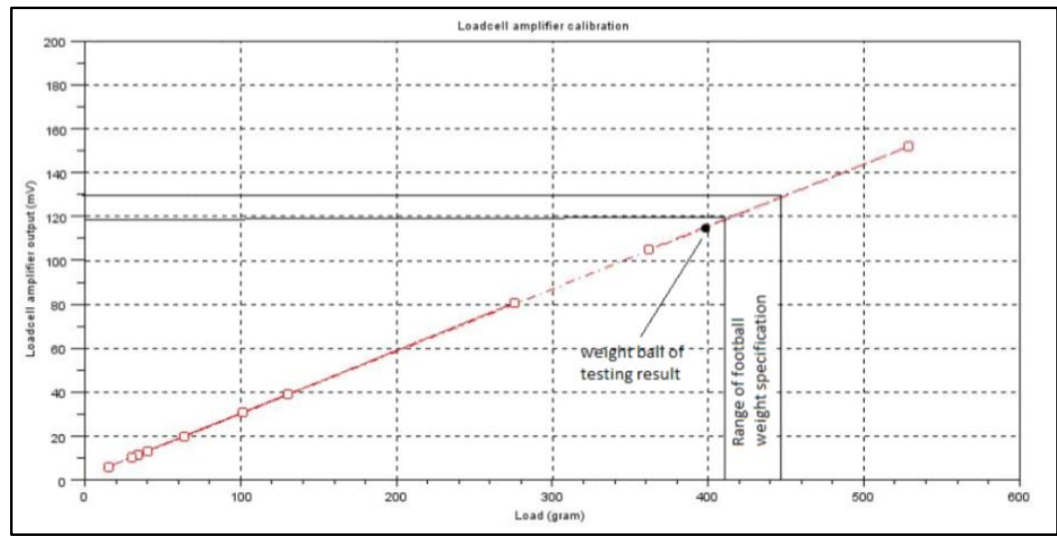

Figure 4. Configuration of the conveyor system 
Liquid Crystal Display (LCD) used in this project shows the value of the measured item. The LCD display is connected to Arduino Uno by using I2C in order to stabilize the display. Figure 5 shows the connection of LCD display to conveyor system using I2C. The first row of the LCD display shows the weight value of the ball in gram $(\mathrm{g})$. The second row determine the size of the ball whether it is size 5 or not. The LCD has been successfully providing a good measurement for the size and weight of the ball.

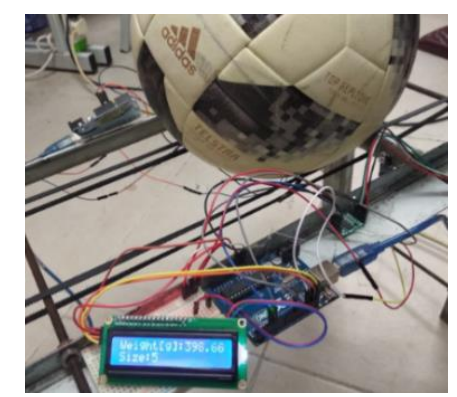

Figure 5. LCD display results with the load

\section{CONCLUSION}

This project has been done by connecting the conveyor system to servo motor, infrared (IR) sensor and load cell sensor through Arduino Uno with the specific coding to make sure the conveyor running according to the algorithm flow. The first sensor is IR sensor that used to measure the size of the ball. If the sensor detects the ball with the standard size, the LCD display will show that the ball is size five (5) ball where if not the display will not show anything. The second sensor is load cell sensor, used to measure the weight of the ball in gram. Before taking the weight measurement, another IR sensor is used to stop the conveyor to record the weight of the ball. This project makes football quality checking easier and faster on production line where it could deliver the Quality Control (QC) supervisor and worker more convenient in their ball quality. For future development, the Automated Conveyor System for Football Quality Checking project can be resize to industrial conveyor size where it can measure for the mass production in lesser time.

\section{ACKNOWLEDGEMENTS}

The authors would like to give special thanks to Universiti Tun Hussein Onn Malaysia (UTHM) under UTHM-Tier 1 Grant No. H136 and Ministry of Higher Education (MOHE) Malaysia.

\section{REFERENCES}

[1] K. Alireza, et al., "Measurement of the mechanical properties of soccer balls using digital image correlation method," Sport Sciences for Health, vol 12, no 1, pp. 69-76; 2016.

[2] Nathan, Alan M., "The effect of spin on the flight of a baseball," American Journal of Physics, vol 76, no 2, pp. 119124, 2008.

[3] Cross, Rod, "Measurements of the horizontal coefficient of restitution for a superball and a tennis ball," American Journal of Physics 70.5: 482-489, 2002.

[4] Hong, Sungchan, et al., "Experiment of aerodynamic force on a rotating soccer ball," Procedia engineering, vol 147, pp. 56-61; 2016.

[5] J. Juliana and A. Ivanov, "Study of soccer ball flight trajectory," MATEC Web of Conferences. Vol. 145. EDP Sciences, 2018.

[6] Asai, T., Seo, et al., "Fundamental aerodynamics of the soccer ball," Sports Engineering, vol 10, no 2, pp 101-109, 2007.

[7] Carré, M.J., et al., "The curve kick of a football, II: flight through the air," Sports Engineering, vol 5, no 4, pp. 193200, 2002.

[8] Potter, A. (2011, December 17). Bayen Munich's Daniel van Buyten hits free-kick so hard the ball bursts [Article]. Retrieved February 15, 2019, from https://metro.co.uk/2011/12/17/bayern-munichs-daniel-van-buyten-hits-freekick-so-hard-the-ball-bursts-258239/.

[9] T. Mizota, et al., "The strange flight behaviour of slowly spinning soccer balls," Scientific reports, vol 3: pp. 1871, 2013.

[10] Takeshi Asai and Seo Kazuya, "Aerodynamic drag of modern soccer balls," SpringerPlus, vol 2, no 1 pp. 171; 2013. 
[11] J. E. Goff, et al., "A comparison of Jabulani and Brazuca non-spin aerodynamics," Proceedings of the Institution of Mechanical Engineers, Part P: Journal of Sports Engineering and Technology. vol 228, no 3, pp. 188-194, 2014.

[12] S. Hong and T. Asai, "Effect of panel shape of soccer ball on its flight characteristics," Scientific reports, vol 4, pp. 5068; 2016.

[13] S. Hong and T.Asai, "Aerodynamic effects of dimples on soccer ball surfaces," Heliyon, vol 3, no 10; 2017.

[14] K. Naito, et al., "Effect of seam characteristics on critical Reynolds number in footballs," Mechanical Engineering Journal, vol 5, no. 1: 17-00369, 2018.

[15] Defraeye, Thijs, et al., "Aerodynamic study of different cyclist positions: CFD analysis and full-scale wind-tunnel tests," Journal of biomechanics, vol 43, no. 7, pp. 1262-1268; 2010.

[16] Barber, S., et al., "Sports ball aerodynamics: a numerical study of the erratic motion of soccer balls," Computers \& Fluids, vol 38, no. 6, pp. 1091-1100; 2009.

[17] Calvin, T., "Quality control techniques for zero defects," IEEE Transactions on Components, Hybrids, and Manufacturing Technology, vol 6, no 3, pp. 323-328; 1983.

[18] Rahman, NNS Abdul, et al., "The internet of things beverages bottle shape defect detection using Naïve Bayes classifier," International Journal of Human and Technology Interaction (IJHaTI), vol 2, no. 1, pp. 71-76; 2018.

[19] Sindhu, et al., "A Study of Cumulative Quantity Control Chart for a Mixture of RayleighModel under a Bayesian Framework." Revista Colombiana de Estadística, vol 39, no. 2, pp. 185-205; 2016.

[20] Panagiotidou, S., et al., "A sequential monitoring Bayesian control scheme for attributes." Quality Technology \& Quantitative Management, pp. 1-17; 2018.

[21] Quigley, John, et al., "Supplier quality improvement: The value of information under uncertainty." European Journal of Operational Research, vol 264, no. 3, pp. 932-947; 2018.

[22] Punyamurthula, Sudhir, and Fazleena Badurdeen, "Assessing Production Line Risk using Bayesian Belief Networks and System Dynamics," Procedia Manufacturing, vol 26, pp. 76-86; 2018.

[23] Oggiano, L., \& Sætran, L., "Aerodynamics of modern soccer balls," Procedia Engineering, vol 2 no 2, pp. 24732479; 2010.

[24] Hutchison, P. (2017, September 11). What is the weight of a size 5 soccer ball? Retrieved February 15, 2019 from https://www.livestrong.com/article/431675-how-much-air-pressure-is-in-a-regulation-size-soccer-ball/.

[25] Arduino, Store Arduino. "Arduino." Arduino LLC (2015).

\section{BIOGRAPHIES OF AUTHORS}

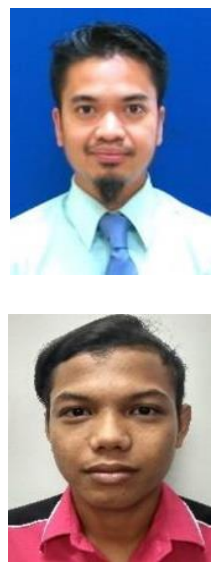

Muhammad Rusydi Muhammad Razif obtained his PhD degrees in in the field of Soft Robotics Engineering from Universiti Teknologi Malaysia, Malaysia. Currently he is working as a lecturer in Faculty of Engineering Technology of the Universiti Tun Hussein Onn Malaysia. His teaching and research interests include robotics, mechanisms, bioinspired, and mechatronics design. He has been the senior researcher of Cybernetics Research Group UTHM and the affiliate researcher of Sustainable Transport and Safety Studies UTHM. He is a member of IEEE and Board of Engineer Malaysia (BEM).

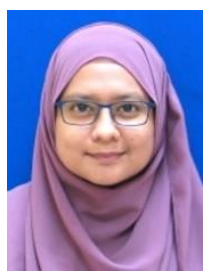

Norazuan Siahaan Amran Harry Juanda obtained his diploma in Electrical Engineering Technology from Universiti Tun Hussein Onn Malaysia, Malaysia. Currently he is further his study in bachelor degree in the same area and institution. He is experienced in solar energy and electrical controlling appliances. He is a member of Engineering Technology Club, UTHM.

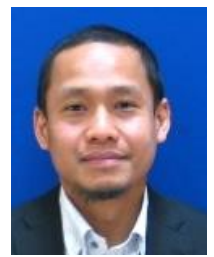

Ili Najaa Aimi Mohd Nordin obtained her B. Eng. Degree in Electrical-Medical Electronics Engineering and Ph.D degree in the field of Soft Robotics Engineering from Universiti Teknologi Malaysia, Malaysia. Currently, she is working as a lecturer in the Department of Electrical Engineering Technology, Faculty of Engineering Technology, Universiti Tun Hussein Onn Malaysia (UTHM). Her main research interests are in the areas of Electronics, Soft Robotics, Rehabilitation Robotics, Machine Learning and Wireless Monitoring. She is currently the head researcher of Cybernetics Research Group (CRG) in the UTHM, a member of Board of Engineer Malaysia (BEM), Institute of Engineers Malaysia (IEM) and Malaysia Board of Technologists (MBOT).

Hairulazwan Hashim obtained his Master degrees in Electrical Engineering from Universiti Tun Hussein Onn Malaysia, in 2007. He is a Senior Lecturer in the Department of Electrical Engineering Technology, Universiti Tun Hussein Onn Malaysia (UTHM). He is currently the Head of Program of Bachelor degree in Electronic Engineering Technology (Industrial Automation) in the Faculty of Engineering Technology UTHM. His teaching and research interests include micro-nano robotics, industrial automation, signalling and communication in biomedical and railway applications. He is a member of IEEE, IEM and MBOT. 